Koninklijke Vereniging voor Nederlandse Muziekgeschiedenis

Haagsche Zomerconcerten in de achttiende eeuw

Author(s): D. F. Scheurleer

Source: Tijdschrift der Vereeniging voor Noord-Nederlands Muziekgeschiedenis, Deel 7, 4de Stuk (1904), pp. 280-289

Published by: Koninklijke Vereniging voor Nederlandse Muziekgeschiedenis

Stable URL: http://www.jstor.org/stable/947959

Accessed: $22 / 06 / 2014$ 05:03

Your use of the JSTOR archive indicates your acceptance of the Terms \& Conditions of Use, available at http://www.jstor.org/page/info/about/policies/terms.jsp

JSTOR is a not-for-profit service that helps scholars, researchers, and students discover, use, and build upon a wide range of content in a trusted digital archive. We use information technology and tools to increase productivity and facilitate new forms of scholarship. For more information about JSTOR, please contact support@jstor.org. 


\title{
HAAGSCHE ZOMERCONCERTEN IN DE ACHTTIENDE EEUW.
}

\author{
DOOR
}

\section{F. SGHEURLEER.}

Onze kennis van het concertleven onzer voorvaderen is nog zóó gebrekkig dat alle bizonderheden dienaangaande, hoe onvolledig ook, dienen bijeen gebracht te worden. Als bouwstoffen kunnen zij later dienst doen. Vooraf mag wel de spijt worden uitgesproken dat de hier achter volgende mededeelingen zoo schaars zijn aan specifiek muzikale bizonderheden; het is evenwel zeer goed mogelijk dat een of andere gelukkige vondst dit later op gewenschte wijze aanvult.

In het midden der 18de eeuw hadden de Hagenaars hun zomervermaak nog niet geheel naar Scheveningen verlegd. Veeleer was hun manier van uitgaan te vergelijken met die van dertig, veertig jaren geleden. Alleen met dit verschil dat de muziekliefhebbers niet naar de "Tent in het Bosch" gingen, maar naar het "Nieuw Vaux Hall, op de Scheveningsche Weg, aen deeze zyde van 't Tolhek".

Dit was een uitspanningsplaats, die nog vele jaren heeft bestaan, al was het in eenigszins gewijzigd karakter. Het was de plaats waar thans de welbekende Koninklijke Bazar zich bevindt, „Boer”, zooals oude Hagenaars nog gewoon zijn te zeggen. D. Boer was het die in December 1839 het logement aldaar, "Duin en Veldzigt" geheeten, aankocht en er zijn zaak vestigde, die later zulk een grooten omvang kreeg. De advertentie aangaande den verkoop van het pand vermeldt, dat het bestond uit een ruim huis met stal en kolfbaan, groote zaal en een tuin met twee koepels. Aldaar was, voor het laatst in 1839, gedurende de Haagsche kermis bal en vauxhall gegeven, met vuurwerk, enz. Ook bij het St. Nikolaasfeest en dergelijke gelegenheden hadden er soortgelijke vermakelijkheden plaats. 
Een eeuw vroeger was het Vaux-Hall geen kermisvermaak. De 's Gravenhaagsche Courant, van 23 Juni 1749, bevat de volgende advertentie:

Mr. Siebers, Casteleyn ran Nieuv Vauxhall, o p den Weg na e r S c heveningen, a $\mathrm{n}$ de日ze zydevan 't $\mathrm{T}$ ol hek maekt bekend, dat hij gesolveerd is, zyne Publicque C'oncerten op aenstaende Donderdag den 26 Juny te beginnen, en daermede weekelyks driemael te continuecren, to weeten $\mathbf{D}$ ing $\mathbf{s}-$ dag, Donderdag en $\mathrm{S} a \mathrm{turdag}$, tot het eynde van de maend Augusty, en zulks op de volgende Voorwaerden: I. Zal het gem. Huys, op de voorn. Drie Dagen, namiddag precies ten 4 uuren geopend, en alle fatsoenlijke Lieden, mits twee Schillingen betaelende, ingelaten worden, dog zallen de Concerten niet laeter als 's avonds 10 uuren duaren. II. Geen Heer, wie hij ook zy, zal het kwalyk mogen nemen, dat het ayt consideratie voor de Dames, aen niemand gepermitteerd zal zyn in de Groote Assemblee Zael te rooken. III. Bij aldien iemand eene byzondere Kamer of Lòge voor zig en zyne Familie of Gezelschap wil huuren, zal dezelve, mits alvorens gewaerschuwd synde, voor hem gereed gehouden worden. IV. Bij Regen of slegt weèr zal men altoos zorg dragen, dat er bekwaeme Rytuygen by de Hand zyn, voor al zoodanige die zig daervan zallen gelieven te bedienen. V. Geene Levery-bedienden, zallen in den Tuyn mogen gaen wandelen. VI. Ook zullen aldaer geen ligte Vrouwspersonen, of die een slegten naem hebben, geadmitteerd worden, en bij aldien zulk eene het waegde aldaer te komen, zal dezelve, zo dra zy ontdekt of bekend word, door de aengestelde Wagten uyt het Huys en de Tuyn gejaagd worden. VII. Ten eynde sig alles in de vereyschte order en geschiktheyd mag toedragen, zal Mr. Siebers, op de voorschreeve Concert-dagen, ter behoorlyker plaetse een genoegzaeme Militaire Wagt ten synen koste verzoeken; beloovende dezelve ook zorg te zullen dragen, dat ieder zo prompt en exact als mogelijk is gediend worde.

Blijkbaar werden de concerten door de voornaamste Haagsche muzikanten uitgevoerd, want reeds een paar dagen later moest de Heer Jozzi berichten, dat hij zijn concert moest uitstellen tot 2 July na kerktyd, omdat hij de in het Vaux-Hall medewerkende muzikanten niet anders "kon krijgen”.

In het begin van Juli werden de concerten gedurende 8 dagen gestaakt wegens „de invallende Voorbereyding" (voor het Avondmaal).

Als direkteur "van het muziek" wordt in volgende advertenties Groneman genoemd, die zou laten executeeren ,eenige Concerten van A. Conelur, waer by hy Waldhoorns heeft gevoegd, als meede eenige extra fraeye andere concerten".

In de tweede week van September hadden slechts twee in plaats van 
drie concerten plaats wegens groote vuurwerken, die afgestoken zouden worden. De toegang kostte die aronden $f$ 1.-

Begin October opende Sicber eene inteekening op acht bals; prijs 8 dukaten. Van concerten is toen geen sprake meer, wel protesteert hij in November ernstig tegen een gerucht, uitgestrooid door ,Quacdaerdige Menschen", als zou hij de stad clandestinelyk verlaten hebben.

Den 30en Maart 1750 lezen wij de volgende advertentie:

Mr. Ems. Sieber, Casteleyn van het Nieuwe Vaux Hall, adverteerd hiermedo aen 't Publicq, en inzonderheyd aan Heeren en Dames, die hem in de voorloedene Zomer met haere tegenwoordigheyd hebben begunstigt, dat hij het bovengenoemde Huys wederom heeft geopend, kunnende aldaer alle fatsoenlijke Lieden bediend worden van allerley Eeten en Drinken, op dezelve voet als in het voorleeden jaer geschied is. De Concerten zullen met de maend May aanvang nemen en door een Orgel geaccompagneerd worden. P. S. In bovengenoemde $\mathrm{V}$ a $\mathbf{a x ~} \mathrm{H}$ all, zijn voor 4 Dacaten te bekomen, Zilvere Lootjes, waer voor een Heer en Dame, den geheele Zomer, zonder dat verder iets behoeven te betalen, de vryen toegang tot de $\mathrm{C}$ on certen zallen hebben.

Zes maal werd deze aankondiging herhaald, eene hardnekkigheid van adverteeren, die op dit gebied nog eene zeldzaamheid was. De uitvoeringen hadden Dinsdags, Donderdags en Zaterdags plaats, het eerste den 9en Mei. Mr. Hellendahl van Leiden voerde een solo ,aen de Fiool" uit.

Den 30en Mei werd het nieuwe orgel ingewijd met een Eere-Zang, gecomponeerd door A. Groneman, op de Vorstelijke Familie van Oranje, voor „verscheyde stemmen”. De compositie verscheen in druk.

Dit jaar had er begin Juli wegens de Voorbereiding alleen Dinsdags concert plaats. Eene belangrijke uitvoering viel op 4 Augustus, de benefite-avond van Groneman

.... en zullen zig ter dier gelegendheyd verscheyde, voornaeme Zangeressen en Zangers laeten komen, en onder anderon een Bas-Cantate nieuw gecomponeerd door een voornaem Heer, \& c. en zullen niet dan de nienwste Concerten van de beroemdste Meesters geëxecuteerd worden, onder anderen verscheyden met Panken en Trompetten, als ook een Concert voor het Orgel obligato. Waervan een gedrukte Lyst zyn zal hoe, en door wien het Mrazik geëxecuteerd word, en zal voor dien dag het entrégeld, in plaats van twaelf stuyvers, eene gulden weezen.

Het blijkt dus dat er gedrukte programma's bestonden. De Stadhouder woonde de avonden van 1 en 4 Augustus bij, even als de 
meeste Hceren en Dames van het Hof en veele andere Personen van distinctie. De uitvoering geschiedde in den tuin.

Half Augustus begonnen de vuurwerken. Omtrent de muzieknummers verneemt men slechts van "nieuwe concerten, geaccompagncerd met Pauken en Trompetten”, en van concerten „Obligat door verscheyde instrumenten". De vuurwerken worden uitvoeriger aangekondigd. Den 19en September was sluitavond.

\section{In 1751 begon Sieber den 31en Maart te adverteeren :}

Mr. Ennst Sieber, Casteleyn van Nieuw raux IIall, op de Scheveningse Weg, bij 's Gravenhage, zal met de Maend May aenstaende, zo dra het Saisoen zulks toelaet, de gewone Ordinares Conserten ter plaetse voornt hervatton, gelyk zy zyn gegeeven geduurende de laatst gepassecrde゚twee Zoomer-Saisoenen, tot genoegen van do respective Heeren en Dames, die dezelve met haere tegenwoordigheyd hebben gelieven te vereeren. Den opgenoemden Casteleyn is thans actucel bezig, met het maeken der daer toe nodige Preparatien, tot het melioreeren en augmentecren der Divertissementen, Illuminatien, Vuurwerken en fraoye nieuw-geinventeerde Embollissementen, \& c. Zullende geduurende het aenstaende Zoomer-Saisoen, worden gohonden 48 Ordinairis concerten, dewelke gelyk voorheenon by de Entrée op de Ordinaire dagen zullen kosten 12 stuyv. en op de digen van Vuurwerken, \& c. 1 gld. voor ieder Persoon, en dus in het geheel bedragen de somme van 40 gl. Tot Encouragement en provisioneel Support der Zwaere kosten; by voorn. Castoleyn ten dien eynde te doen, offereert hy acn den Adel en verdere Hceren en Dames, van nu af aen, tot en met den laetsten April deezes Jaers, de volgende Conditien van Inteekeninge, waer voor de Entríe-Lootjes zullen worden gegeeveu, als: 1. Voor ieder onkeld Heer die de voorsz. 48 Conserten zal gelieven tr frequentecren de somme van 4 Ducaten of 21 Guldens Hollands Conrant. 2. Foor iedor Heer, die telkens eere Dame wil meede brengen, de somme van 6 Ducaten of cenen-dertig Guld. en 10 st., zonder meer. Aen de resp. Inteekenaers van beyde Classen zal 't vrystaan, wanneer het hen niet convenieert op do con of de andere Concort-dagen in Persoon te versebynen, derzelver Lootjes naer believen aen andere to mogen leenen on over to geeven, om van het regt der vrye Entrée te jouïsseeren. De Lootijes zullen door de Heeren Inteekenaers bij derzelver extraditie worden botaeld, en de privisioneele inschrijving geschied van nu af aen in het bovengem. Niew Vaux-Hall.

Den 21en en 28en April volgden deze advertenties:

Erasest Sirber, Casteleyn van Nieuw Vaux-Hall, adverteord mits dezen aen alle respective Heeren en Dames, dat het voornoemde Huys, van nu af aen, wederom geopent, en veel commoder, dan ooyt van te vooren, geapproprieert is, tot Receptie van Gezelschappen, en het houden van Maeltyden en Collations: Zynde voorzien van allerhande excellente Wynen in zoorten, een experte Kok en alerte Domestiquen, tot smaek en genoegen van alle de geene, dewelko hem met dezelver presentie zullen gelieven te vereeren, alles tot modique en raisonnable Pryzen. Hot precies begin der Concerten zal nader geadverteerd worden. 
Emarast Steber, Casteleyn van Nieuw Vaux-Hall, volgens vorige bekendmakingen, het voorsz. Huys, ter receptie van Gezelschappen, wederom geapproprieert en geopent hebbende, adverteert aen alle respective Heeren en Dames, dat aldaer op Dingsdag den 4 May aenstaende, een extra ordinaris Vocael- en Instrumentael-Concert zal worden gehouden, ter occasie van de verjaering der Electie van Zyne Doorluchtige Hoogheyd, tot Stadhouder deezer Provincie. De Entrée is één Gulden, en het begin gefixeert ten 11 uuren voor de middag, om de koele Avond-lugt te vermyden. By tussenpozinge der Maziek zallen de respective Heeren en Dames gediverteert worden met het spectakel van te zien klimmen op een met Oly en Zeep besmeerden Mast, ter hoogte van 60 voeten, naer een prys van vyf Ducaten en een Tractement, voor den geene die eenen krans van deszelfs Top zal kunnen afhaelen. Wordende te gelyk alle Matroozen en Liefhebbers van klimmen uytgenodigt, om hare Kunst, Bequaemheyd en Fortayn, tot het behaelen dier Praemie, te komen probeeren.

$\mathrm{Bij}$ herplaatsing van laatstgenoemde aankondiging op 30 April was nog een postcriptum toegevoegd:

N. B. Op de bovengenoemde dag zal een Ordinaire Tafel gehouden worden voor Heeren, die aldaer het Middagmael gelieven te houden en 30 stuyvers voor ieder Persoon moeten betaeld worden, en werden de Heeren en Dames verzogt, welke dien dag aen een aparte Tafel zoude willen spyzen, zulks daegs te vooren te laeten weeten.

\section{Den 5en Mei las men:}

Ermest Sieber, Casteleyn van Nieuw Vaux-Hall, adverteert mits deezen, dat hy het houden van Ordinaire Tafel, geduurende deeze Maend May, zal continueeren, à 30 stuyvers voor ieder Persoon, zullende de Ordinaire Concerten zijn aenvang neemen op Donderdag over agt dagen, zullende zijn den 13 May, en zal dien avond een Superbe Vuurwerk, het geen aen voorn. Casteleyn, door een voornaeme hand, present gedaen is, afgestoken worden; en dien dag .voor Entrée-geld moeten betaeld werden ééne gulden. Voorts zullen de Ordinaire Concert-dagen, geduurende het Zoomer-Saysoen gehouden worden, op Dingsdag, Donderdag en Saturdag.

\section{Den 12en Mei was er het volgende Nota Bene:}

N. B. De Heeren en Dames, welke dien dag aen een aparte Tafel zonde willen spyzen, werden verzogt zulks heeden te laten weten.

Vijf dagen later maakten de kwaadsprekers weder eene rectificatie noodig. Het blijkt echter dat de Hagenaars toen ook al eens getracteerd werden op niet bijster geslaagd vuurwerk :

Mr. ERNest Sieber, Casteleyn van het Nieuw Vaux-Hall, adverteert, dat zyne Ordinairo Concerten haeren regulieren voortgang zullen hebben, 3 mael 's weeks, 
te weeten Dingsdags, Donderdags en Saturdags. En dat op Morgen, zynde Dingsdag den 18 May, 's avonds ten 8 uuren, wederom op een Mast, tot playzier van de Heeren en Dames, welke zulks nog niet gezien hebben, zal geklommen worden, en zal het Entrée-geld maer 12 stuyvers zyn,

P.S. De bovengenoemde SIEBEr niet dan met de ayterste verwondering vernomen hebbende, dat eenige quaetspreekende Menschen uytgestrooyd hebben, dat dezélve aen de Persoon, die den 4 May in het gem. Vaux-Halle op de Mast geklommen heeft, de beloofde prys van 5 Ducaten niet zoude betaeld hebben, zo adverteerd dezelve, dat zalks t'eenemael valsch en verdigt is, en hoopt niet dat het Publicq hem, die alle moeyte aenwend en geen kosten ontziet om een ieder playzier te doen, zalks zal opleggen. En alzo hy ook vernomen heeft, dat het vuurwerk, het welk den 13 dezer is afgestoken, aen het Publicq niet al te wel voldaen heeft, zo zal dezelve, alhoewel de schuld diesweegens op hem niet te wyten is, om zijn oplettendheyd te toonen en het Publicq beeter te voldoen, op Dingsdag den 25 May een magnific Concert geeven, en zal dienzelven avond een Vuarwerk afgestoken worden, dat hy niet twyffeld, of zal het Publicq behaegen.

Het laatste mastklimmen, dat zeker verband hield met de Haagsche kermis, die den tweeden Maandag van Mei inviel, had den 22en Mei plaats. Ook de koude, die zich bij die beroemde feestviering zoo dikwijls liet gevoelen, bleef niet achterwege. Dit blijkt uit de advertentie van den $24 \mathrm{en}$. Het was zulk slecht weer, dat de Stadhouder zijn reis naar Zeeland moest uitstellen. Het was dus geen uitvlucht.

Mr. ERN. Sieber, Casteleyn van het Nieuro Vaux-Hall, adverteerd, dat Morgen en aenstaende Donderdag geen Concert zal werden gegeeven, weegens de aenhoudende koude Avond.lugt, en dat het meergenoemde Vuurwerk niet Morgen den 25 May, maer toekomende Saturdag, zynde den 29 May, zal afgestoken worden, verzeld door een superbe Concert, niet twyffelende of zal het Pablicq behaegen.

Zeer te betreuren is de onvolledigheid der advertenties. De belofte van iets ten gehoore te zullen brengen "van een voornaam componist" scheen vaak voldoende, doch nu en dan duiken ook werkelijk bekende namen op, b.v. die van HäNDEL :

Mr. Ernest Sirber, Casteleyn van 't New Vaux-Hall, adverteerd, dat hy zyne Concerten 3 mael ter week, te weeten des Dingsdags, Donderdags en Saturdags; geduurende het Zomer-sayzoen, zal continueeren en dat ieder arond 2 nieuwe simphonien, geaccompagneerd met Pauken en Trompetten, zullen geërecuteerd worden, welke gemaekt zijn door een voornaem Componist. De bovengenoemde Casteleyn zal altoos tragten de Aenhoorders met het beste Musicq te diverteeren en toekomende Donderdag en Saturdag zal de Overture met de Marsch en keurlyke Minuet ayt $\mathrm{Mr}$. HeNdeLs Oratorie van SAUL, welke van alle kenners 
der Musieq, voor een der beste van allo zyne werken gehouden, en nonyt in het Vaux-Hall geëxecutoerd is, geschieden. (14 Juny.)

En Händel scheen in den smaak te vallen, want er hadden herhalingen plaats :

N B. Morgen on nenstaende Donderdag zullon verscheydo nionwo Concerten gespeeld worden, met do repetitio van hel Musicq van Mr. Henders Oratorie van $S_{\Lambda}$, , 't wolk, geduurende de voorleedene weok, tot genoegen van de Toehoorders is geëxecuteerd geworden. (21 Juny.)

Einde Juni vielen er weder concerten uit „vermits het invallende nagtmael", maar half Juli komen er nieuwe aantrekkelijkheden:

Mr. Erast Sieber, Casteleyn van Nero Vaux-Hall, adverteerd het Publicq, dat op Morgen, zynde Dingsdag den 13 Jaly, en de daer aen volgende Donderdag, in voornoemde Tayn gerepresentecrd zal werden een Masker Dans met cen beweegende Illaminatie, die zig geduarende den Dans in verscheyde formen zal veranderen, waer door do boschouwers een aengonaem gezigt zullen erlangen. Het Entréegeld zal 3 Sesthalven zyn.

De bezoekers zouden echter nog belangrijker dingen te hoolen krijgen, b.v. eene compositie, gemaakt op een vuurwerk:

Ernest Sieber, Casteleyn van het Nicuwe Vaux-Hall, in 's Hage, adverteerd by deczen, dat op aenstaende Saturdag, zullende zyn den 17 deezer, een Nieuw Concert, gecomponeerd door den vermaerden Muziekmoester en Componist Monsr. ZoLsity zal geëxecuteerd worden; hebbende het zelve betrekking op alle de differente stukken van een superbe Vuurwerk, dat gelyk staet afgestoken te worden, verzeld met con Pantomine, genoemt Orpheus en Erodice. Twyffelende niet, alzo hy al zyn devoir staet aen to wenden, om zo wel het vaurwerk als hot een en ander plaisierig en aerdig to maeken, of zal het publicq behagen en groot genoegen geeven; zullende het Entrée-geld voor dien diag eene Gulde weezon.

N.B. In het bovengenoemde Vaux-Hall zal by de Intrée gratis te bekomen zijn, do gedrakte Explicatie, zo wel van de Pantomime als het een en ander, dat aen de Liefhebbers zal vertoond worden; verzoekende hij alle Heeren en Dames, die Collations willen bespreeken, zulks daegs te vooren te doen, ten eynde dezelvo des te beeter kunnen worden bediend.

Morgen avond, zynde Donderdag den 15 July, zal de Nieawe Masker-Dans, dio gisteren gedaen is, woderom geschieden. (14 Jull).

Pantomime en Maskerdans beleefden meerdere uitroeringen: er kwam bovendien nog een Zwaardendans bij, (22 Juli). 
Einde Juli vinden wij herhaaldelijk den componist ZoLsnirz vermeld, met nieure symphoniën en eene nieuwe ouverture.

Vermoedelijk hebben wij hier te doen met werken van den Leidschen componist Anton Wilhelm Solnitz, die, volgens Gerber, in 1758 op 36 jarigen leeftijd stierf en alleen kon componeeren.... wanneer hij dronken was!

De vuurwerken bleven een groote rol spelen en in verband daarmede moest met het weder rekening worden gehouden:

Mr. Eravest Simber, Casteleyn van New Vaux-Hall, adverteerd bij deezen, dat op Morgen, zynde Dingsdag den 10 Augusty 1751, een axtraordinair fraey Concert gegeeven, en 's aronds ten 10 uuren een kostelijk Konst-Vuarwerk, het geen door een voornaem Meester vervaerdigt is, zal afgestoken worden, zullende onder andere worden vertonnd een Zon, welken den geheelen avond zal branden, ook zal den Konst-Vuurwerker vertoonen een levendig Mans-persoon, welke zig gestadig in een $\mathrm{zwaer}$ vuur bevinden zal, en van welkers Lighaem allerhande zoorten van vuurwerken zullen afvliegen. Het Entrée-geld zal voor dien dag een Gulden zyn. N.B. Alzo op laetstleeden Saturdag, weegens het reegenagtig weêr, geen vuurwerk afgestooken is, maer aen de present zynde Heeren en Dames Lootjes zyn uytgedeeld, om daer van by het naeste vuurwerk gebrayk te kunnen maeken, zo worden dezelve by deezen op het vriendelykste verzogt, zulks op Morgen te willen doen, alzo anders de Lootjes voor vervallen zullen gehouden worden. (9 Augusty.)

Orpheus en Euridice zou den $14^{\text {en }}$ Augustus weder gemaakt worden, maar op nieuw was het slechte weer een hinderpaal. Ditmaal had er naar het schijnt een wolkbreuk plaats gehad:

Mr. Ennegt Srrber, Casteleyn van het New-Vaux-Hall, adverteerd bij deezen, dat op verzoek van veele Lieden van de eerste Rang, op Morgen, zynde Dingsdag den 17 Augusty 1751, een superbe Concert en Vuurwerk, benevens de Explicatie van Orpheus en Euridice, zal geëxecuteerd worden, en indien het onverhooptelyk geheel reegenagtig weêr was, zo zal egter het Concert gegeeven en het Vuurwerk afgestooken worden. Het Ėntrée-geld zal voor dien avond een Gulden zijn.

P.8. Op laetsleeden Saturdag heeft men de Explicatie van Orpheus en Euridice niet kunnen vertonen, vermits, door de zwaere Reegens, meer dan 4 voeten water onder het Theater stond.

En toen het vergevorderde seizoen was ingetreden werden er weder groote aantrekkelijkheden" verzonnen. De combinatie van programmamuziek en vuurwerk scheen aan de orde van den dag: 
Envest Sieber, Casteleyn van New Vaux-Hall in 's Hage, maekt hier meede bokend clat nademael hy voor het eyndigen van het tegenwoordige Saisoen, de Liefhebbers nog gaerne eenige divertissementen wilde aendoen, hij op Donderdag den 26 Augusty, zal geeven een magnificq Concert, waer van de nieuwe Musieq, door den vermaerden Zollsitz gecomponeerd, de diverse Hartstogten van Liefde, Hrestigheyd en andere, die in de Historie van Ulysses en Circe voorkomen, zal aytdrakken, als meede een superbe Vuarwerk, insgelijks op de borengenoemde Eistorio betrekking hebbende. En nademael hij, zo voor het een als het ander geen moeyte nog kosten gespaerd heeft, zo twyffeld hij niet of het zal de Aenschouwers behagen. Aen bovengenoemde Vaux-Hall zal dien avond een gedrukte Explicatie gratis te bekomen, en het Entrée-geld egter niet meer als een gulden zijn.

N.B. De bovengenoemde Castelyn adverteerd nog, dat hij voorzien is van een zecr habile Kok, derhalven worden de Heeren en Dames, die soupées gclieven te bespreeken, verzogt, zulks daegs te vooren te doen.

Natuurlijk werd de verjaardag van den Stadhouder luisterrijk gevierd:

Mr. Errest Sicber, adverteerd, dat hij op aenstaende Donderdag den 2 September, de Geboorten-dag van Syn Doorlugtige Hoogheyd, den Heere Prince Erf-Stadhouder, in het Nieuwe Vaux-Hall, zal celebreeren; zullende ter dier occasie een superbe Vuurwerk afgestoken worden, en zal onder anderen de Naem van Syn Hoogheyd, in een Blaeuw vaur, branden en door een Zon bestraeld worden; ook zal een nieuwe Ode, waer toe het Musicq door Mr. Zolnitz gecomponeerd is, ter eere van Syn Hoogheyd gezongen, en verscheyde andere nieuwe Simphonies en Ouvertures geëxecuteerd worden. Het Entrée-geld zal dien avond een Gulde zyn. N.B. Morgen avond zal ook een superbe Concert gegeven worden.

$\mathrm{Nu}$ volgden weldra de laatste advertenties. Het voorjaar was koud, de zomer regenachtig geweest. Het najaar was onstuimig:

Mr. Ernest Sieber, Casteleyn van New-Vaux-Hall, adverteerd, dat, dewijl het Zomer-sayzoen geeyndigt is, hy aenstaende Saturdag den 11 September 1751, voor de laetstemael Concert zal houden, en dat dien avond de beste en uytsteekenste Simphonies en Ouvertures van de eerste Meesters zollen geëxecuteerd, ten 10 uuren een fraey Vuurwerk afgestoken worden, en daer meedo de Divertissementen in het Vaux-Hall voor dit sayzoen zullen eyndigen.

P.S. De bovengenoemde Ernest Sibber bedankt te gelyk alle Hecren, Dames en andere Personen, welke hem de eer aengedaen hebben, zijne concerten, \&c. by te woonen, recommandeert zig verder in haer gunst, en presenteert, indien het mooye weêr nog verder mogte continueeren, en het Publicq daer in behagen schepte, om voorts nog eenige tyd éénmaal ter week Concert to houden. (8 September.)

Mr. Eranest Sieber, Casteleyn van Neto-Vauxhall, adverteerd, dat dewyl door het omstuymig weêr, op de gespecificeerde dagen het beloofde Vnurwerk niet 
heeft kunnen afgestoken worden, hij voorneemens is zalks op Morgen, zynde Saturdag den 18 September 1751, te doen en zal alsdan voor de laetstemael Concert gehouden worden.

N.B. De Heeren en Dames, welke dien avond zallen gelieven te soupeeren, werden verzogt zalks heoden te laeten bestellen, alzo geen andere Spys als gekookte Ham en gebraden Vlees gereed gehouden zal worden. (17 Septomber).

In latere jaren heb ik geen advertenties van SIEBER of zijn vauxhal gevonden. Misschien waren de rondgestrooide ongunstige praatjes niet zoo geheel ongegrond geweest en hoogst waarschijnlijk heeft de dood van Priss Wirlem IV, die slechts twee jonge kinderen naliet, op dergelijke vermakelijkheden vernietigend gewerkt. 